\title{
Gênero, sexualidade e protagonismo juvenil: relato de uma experiência no CEFET-RJ
}

\author{
Gender, sexuality and youth protagonism: report of an experience in \\ CEFET-RJ
}

Recebido: 19/06/2020 | Revisado: 09/11/2020 | Aceito: 26/04/2021 | Publicado: 16/06/2021

\section{Cristiana Rosa Valença}

ORCID: https://orcid.org/0000-0000-00000000

Centro Federal de Educação Tecnológica (CEFET)

E-mail: crisrvalenca@gmail.com

Keila Lucio Carvalho

ORCID: https://orcid.org/0000-0003-03911179

Centro Federal de Educação Tecnológica (CEFET)

E-mail: keilalcarvalho@gmail.com

Como citar: VALENÇA, R. C.;

CARVALHO, K. L.; Gênero, sexualidade e protagonismo juvenil: relato de uma experiência no CEFET-RJ. Revista Brasileira da Educação Profissional e Tecnológica, [S.I.], v. 1, n. 20, p. 1-12 e10516, jun. 2021. ISSN 2447-1801.

This work is licensed under a Creative Commons Attribution 4.0 Unported License.

\section{Resumo}

Este relato busca refletir sobre uma experiência de abordagem sobre relações de gênero e sexualidade envolvendo estudantes do ensino médio integrado da unidade Maracanã do Centro Federal de Educação Tecnológica Celso Suckow da Fonseca (CEFET-RJ) durante o ano de 2019. Através do projeto "Sexualidade, Gênero e Diversidades na Juventude", foi construída uma experiência de pesquisa-ação que dialogou sobre questões relacionadas à sexualidade juvenil nas suas dimensões biológicas, sociais e políticas. Por isso mesmo, a experiência esteve suscetível a seguir caminhos traçados pelas demandas dos próprios estudantes. Consideramos que, além de promover a educação sexual, a educação profissional e tecnológica precisa incluir, especialmente, as experiências das jovens estudantes mulheres e lgbt's.

Palavras-chave: Juventude. Gênero. Sexualidade. Educação Sexual. Protagonismo Juvenil.

Abstract

This report seeks to reflect on an experience of approaching gender relations and sexuality involving high school students from the Maracanã unit of the Federal Center for Technological Education Celso Suckow da Fonseca (CEFETRJ) during 2019. Through the project "Sexuality, Gender and Diversity in Youth", an action research experience was built that was dialogued on issues related to youth sexuality in its biological, social and political dimensions. Therefore, the experiencie was susceptible to follow paths traced by demands of the students themselves. We considered that, in addition to promoting sex education, professional and technological education need to include, especially, the experiences of young women and LGBT students.

Keywords: Youth. Gender. Sexuality. Sexual Education. Youth Protagonism. 


\section{O LUGAR DO GÊNERO E DA SEXUALIDADE NA ESCOLA DE EDUCAÇÃO PROFISSIONAL E TECNOLÓGICA}

\section{O Centro Federal de Educação Tecnológica Celso Suckow da Fonseca} (CEFET-RJ) é parte da Rede Federal de Educação Profissional e Tecnológica e oferece cursos técnicos integrados ao ensino médio, subsequentes (pós-médio), tecnológicos, de graduação e de pós-graduação lato sensu e stricto sensu (mestrado e doutorado), nas modalidades presencial e à distância. Na unidade Maracanã, os cursos integrados ao médio compreendem administração, segurança do trabalho, guia de turismo e cursos tradicionalmente masculinos como edificações, eletrônica, eletrotécnica, estradas, informática, mecânica, meteorologia e telecomunicações.

O histórico das instituições de Educação Profissional e Tecnológica remonta a divisão entre educação propedêutica, de caráter mais humanista e geral, e a educação profissional, voltada para a formação da classe trabalhadora para o trabalho (SAVIANI, 2007), no sentido de contribuir para o desenvolvimento econômico através da formação de quadros para a indústria e para o setor de serviços. No interior desse modelo profissional e tecnológico são reforçadas construções sociais de gênero que atribuem aos homens maior "competência técnica" (HIRATA, 2003).

Segundo Joan Scott (1995, p. 86), o gênero é um "elemento constitutivo de relações sociais baseadas nas diferenças percebidas entre os sexos", ao mesmo tempo em que é uma "forma primária de dar significado às relações de poder", "por meio do qual, o poder é articulado" (SCOTT, 1995, p. 88). Ou seja, a educação profissional técnica de nível médio é representativa da desigualdade das relações de gênero: marcadores e estereótipos influenciam tanto nas escolhas profissionais dos/as estudantes quanto nas situações do cotidiano escolar que reproduzem as opressões ligadas ao gênero e à orientação sexual.

Convém lembrar que é no ambiente escolar que os jovens passam grande parte de seu cotidiano. Embora a escola seja um espaço de aprendizado e de convivência, o "viver com" é frequentemente suprimido no discurso e na prática pedagógica (SPOSITO; GALVÃO, 2004). Alguns autores como Júnior, Oswald e Pocahy (2018) têm se dedicado a informar o modo como jovens interpelados em posição abjeta negociam e reinventam suas vidas a partir das redes de subjetividade e de significação que se constituem à margem das instituições que supostamente protegeriam esses sujeitos - a escola deveria ser uma dessas instituições protetoras, o que, infelizmente, nem sempre ocorre.

Seguindo Judith Butler, estes autores entendem a abjeção como uma operação que faz algo ou alguma coisa "permanecer indizível para que os regimes de discurso contemporâneos possam continuar a exercer seu poder" (BUTLER, 2004, p. 217). Desse modo, sobre os corpos que fogem à norma incidem tentativas de conformação, docilização ou eliminação porque performam diferente dos padrões aceitáveis, "perturbando" o sistema ou determinada ordem social. Os corpos abjetos, portanto, são tidos como estranhos, repulsivos e ilegítimos enquanto os corpos que importam em sua existência são reconhecidos e legitimados como corpos que importam. Ao mesmo tempo, os corpos abjetos insistem em ser visíveis revelando a dimensão política do corpo, em sua coletividade. Na escola isto não é diferente.

Se, por um lado, diversos dispositivos no ambiente escolar reforçam as estruturas de poder através da docilização dos corpos que conformam ideais de 
comportamento e de subordinação - através da legitimação de certos saberes e da vigilância da comunidade escolar, por exemplo - por outro lado, "as resistências são o outro lado nas relações de poder" (FOUCAULT, 2003, p. 91). Não são incomuns, no cotidiano escolar, episódios de insubordinação que podem se revelar, inclusive, pela reivindicação de espaços de protagonismo juvenil que colocam a sexualidade e o debate sobre gênero no centro dessa resistência.

Na maioria das sociedades contemporâneas, ao nascer a criança é educada segundo padrões de gênero rigorosos associados ao sexo biológico. Esse processo envolve uma pressão social e familiar para que o indivíduo, ao crescer, se sinta atraído por uma pessoa do sexo oposto. Tais constrangimentos se refletem e acontecem, também, intramuros escolares. Ainda que tacitamente, os profissionais da educação exigem determinados padrões de comportamento. Além disso, não podemos desconsiderar a pressão dos próprios colegas, além da preocupação dos próprios jovens estudantes em não decepcionar sua família por conta de suas dissidências dos padrões socialmente construídos de gênero e de orientação sexual.

Por se constituir em uma dimensão fundamental do ciclo de vida de homens e mulheres e envolver práticas e desejos ligados à satisfação, à afetividade, ao prazer, aos sentimentos, ao exercício da liberdade e à saúde, a sexualidade é uma das principais questões de interesse das juventudes. Ao mesmo tempo em que os jovens têm especial interesse e curiosidade a respeito da sexualidade, eles já possuem um repertório sobre o assunto, por vezes com informações fragmentadas, incompletas ou já "prontas", reproduzindo estereótipos e estigmas que, inclusive, podem não corresponder à sua própria condição e/ou orientação sexual (LOURO, 2003; MACEDO et al., 2013).

Além disso, nos últimos anos, é possível notar um aumento no número de casos de Infecções Sexualmente Transmissíveis - IST's (anteriormente chamadas de DST's), principalmente da AIDS (causada pelo vírus HIV), sífilis e HPV especialmente entre os jovens (BRASIL, 2012). As razões para esse aumento parecem se dever à diminuição do número de campanhas de prevenção, ao fato de que a geração atual de jovens não vivenciou a epidemia de AIDS da década de 1980 e porque as informações disponíveis nos veículos/espaços oficiais (governamentais, educacionais e mídias em geral) são, em sua maioria, bastante formais, o que acaba reduzindo a eficácia da informação ao público jovem.

Estudos têm apontado como relevante o desenvolvimento de abordagens educativas para promoção da saúde sexual e reprodutiva de adolescentes de forma a colaborar para a prevenção de IST's e minimizar problemas emocionais e sociais (ANDRADE et al., 2012; BAUMFELD et al., 2012).

Com base no exposto, temos claro que é imperativo e oportuno abordar na escola questões relacionadas ao gênero e à sexualidade, bem como atuar claramente em defesa das liberdades individuais e coletivas e do respeito às diversidades. Isto se torna especialmente importante no contexto de uma escola de educação tecnológica e profissional historicamente sexista, que reproduz a tradicional divisão sexual do trabalho e os estereótipos de gênero nos mais variados e heterogêneos discursos e práticas, institucionais ou não.

Esses elementos reforçam a necessidade permanente da abordagem sobre as relações sociais de gênero, sobre a sexualidade e a educação sexual, de forma ampla. Nos últimos anos, essa necessidade vem sendo apresentada como uma 
reivindicação que parte dos/as próprios/as estudantes, como foi o caso de um projeto de abordagem sobre gênero e sexualidade que envolveu estudantes do ensino médio integrado da unidade Maracanã do CEFET-RJ durante o ano de 2019. Este trabalho objetiva relatar e trazer reflexões sobre essa experiência.

\subsection{GÊNERO E SEXUALIDADE NA PERSPECTIVA DA EDUCAÇÃO EM DIREITOS HUMANOS: QUANDO OS ESTUDANTES SÃO OS PROTAGONISTAS}

Em uma conjuntura de acirramento de conflitos político-ideológicos envolvendo os direitos sexuais e reprodutivos em face do avanço do conservadorismo e da legitimação dos discursos de ódio e de violências, o fomento a uma cultura de combate a essas desigualdades e opressões se torna ainda mais necessária. Além disso, no cenário atual no mundo e no Brasil temos visto um intenso debate em torno de aspectos da sexualidade e questões de gênero, como por exemplo, a reivindicação pela descriminalização do aborto, a luta pela igualdade de direitos entre os gêneros, a grande incidência da violência sexual e de gênero e as reivindicações de grupos LGBTQIA+ por políticas públicas que os contemple.

As instituições escolares e o campo educacional, como um todo, são refletidas pelo acirramento de disputas ideológicas e políticas, mas não podemos desconsiderar que o inverso também acontece. A educação profissional e tecnológica não pode estar descolada de uma formação humanista que, indissociavelmente, repercuta positivamente no enfrentamento de racismos, machismos, LGBTQIA-fobias e outras opressões e desigualdades que se fazem presentes na sociedade.

Em um momento em que a abstinência sexual está sendo invocada como política estatal de saúde pública para jovens, a educação sexual torna-se tema urgente que precisa ser mobilizada dentro das escolas. Além de claramente heteronormativa, a ilusão da abstinência sexual associada à falta de conhecimento e diálogo claro sobre o corpo humano, suas funções e sua sexualidade, gera um efeito perverso para os jovens, que, de forma geral, pensam e querem se informar sobre sexo. Não falar com os jovens apenas muda a fonte de informação, que passa a ser a informal e com efeitos extremamente deletérios.

Por outro lado, a necessidade de educação sexual tira do silenciamento a sexualidade, ainda tão marginalizada na nossa sociedade. Quando inserimos a temática sobre sexualidade de modo franco e aberto, inclusive no ambiente escolar, essa abordagem pode se transformar em aprendizado e a dimensão da sexualidade passa a ser entendida como um direito humano.

Os direitos humanos são direitos e liberdades básicos, fundamentais para a dignidade e garantidos a todos os cidadãos de qualquer parte do mundo, sem discriminação como cor, religião, nacionalidade, gênero, orientação sexual ou política. Os direitos sexuais são direitos humanos universais, reconhecidos em leis nacionais e documentos internacionais. Por isso mesmo, a educação sexual é tão necessária, já que ela corresponde a uma forma de fazer valer os direitos sexuais juvenis, contribuindo para que se tornem mais conscientes e, também, mais responsáveis em sua atitude e comportamento. Além disso, a educação sexual propicia o empoderamento da juventude para os desafios sociais, afetivos e emocionais que enfrentam nesse processo. 
Ainda hoje, existe uma dificuldade, mesmo no ambiente escolar, em dialogar sobre a juventude. Ora é infantilizada como um tempo de "aborrecentes", ora adultizada. A juventude é um período de desenvolvimento neurológico e biopsicossocial e precisa ser compreendida a partir de si mesma. Torna-se importante, portanto, gerar reflexões e discutir valores sociais estabelecidos ouvindo os próprios jovens, colocando-os no centro da ação de experiências cujo enfoque são eles mesmos. Neste sentido, a perspectiva da Educação em Direitos Humanos a partir do protagonismo juvenil contribui para a construção de espaços de reflexão e de ação sobre gênero e sexualidade, muitas vezes considerados polêmicos e, equivocadamente, até mesmo tabu.

A Educação em Direitos Humanos é uma educação permanente, continuada e global, voltada para a mudança, e "é uma inculcação de valores, para atingir corações e mentes e não apenas instrução, meramente transmissora de conhecimentos" (BEVEVIDES, 2000, p.1). É ainda, uma educação contra-hegemônica (ESTÊVÃO, 2002a; 2002b). Não menos importante, é preciso entender que a Educação em Direitos Humanos é feita na interação entre educadores e educandos, ou seja, não é um protocolo fechado e burocrático aplicado aos estudantes, mas uma educação baseada na vivência do valor da igualdade em dignidade e direitos para todos devendo, por estas características, propiciar o desenvolvimento de sentimentos e atitudes de cooperação e solidariedade.

Ao mesmo tempo, o aprendizado, deve levar ao senso de responsabilidade segundo o qual torna-se possível perceber as consequências pessoais e sociais de cada escolha feita pelos estudantes formados sob esta perspectiva. Uma educação sob a perspectiva dos direitos humanos intenciona formar cidadãos participantes, críticos, responsáveis e comprometidos com a transformação das práticas e condições sociais que violam ou negam os direitos humanos.

Desta forma, a Educação em Direitos Humanos se constrói e reconstrói nos cotidianos escolares numa perspectiva dialógica, sem a qual essa educação não aconteceria. Busca, portanto, continuamente uma mudança cultural uma vez que seu principal objetivo é tornar o espaço escolar uma esfera pública democrática, operando no sentido oposto à reprodução e legitimação das desigualdades sociais. Nessa relação se destacam, segundo Candau (2008), três elementos constituintes: educar para formar sujeitos de direito, educar para o favorecimento dos processos de "empoderamento" de sujeitos e populações marginalizadas e educar para o "nunca mais".

Observando estes princípios, o projeto "Sexualidade, gênero e diversidades na juventude", desenvolvido no CEFET-RJ, foi uma iniciativa que tomou forma a partir das demandas apresentadas por estudantes, no sentido da necessidade de construção de uma experiência de pesquisa-ação que buscasse dialogar as questões relacionadas à sexualidade juvenil nas suas dimensões biológicas, psicológicas e sociológicas.

Para tanto, retomamos a experiência inicialmente desenvolvida em 2016 com o projeto "Conversa entre jovens: discutindo a sexualidade" e, nesta proposta remodelada, foram incorporadas novas demandas oriundas do cenário político e social atual que repercutem na organização escolar e se fazem presentes no cotidiano das e dos estudantes. 


\section{METODOLOGIA}

Considerando o exposto, foi criado o projeto de extensão Sexualidade, gênero e diversidades na juventude por duas docentes, uma de biologia e outra de sociologia, a partir das demandas de estudantes de ensino médio do CEFET-RJ da Unidade Maracanã. O projeto teve o objetivo geral de abordar assuntos que envolvem a vida sexual, identidade sexual, questões de gênero e prevenção às ISTs em uma conjuntura política e social de intensa interação entre adolescentes (BEHRENS, 2002), tanto da comunidade escolar interna quanto externa, a partir da criação de espaços de debates e ações desenvolvidos ao longo do projeto.

O referencial teórico-metodológico que orientou a experiência foi a pesquisaação (COGHLAN; BRANNICK, 2008; THIOLLENT, 2005). A partir deste referencial, a metodologia do projeto esteve aliada à ideia de protagonismo juvenil, entrelaçando o ensino, a pesquisa e a extensão, uma vez que o foco está na mudança de determinada situação ou realidade social - aqui nos interessa refletir sobre a produção do conhecimento gerada pela experiência. Desse modo, as atividades foram realizadas de forma a fortalecer o engajamento juvenil, tornando os estudantes co-responsáveis e, também, responsáveis pela idealização, divulgação e execução das atividades desenvolvidas.

Integraram o projeto 11 estudantes do ensino médio integrado (sendo uma delas bolsista de extensão e os demais, voluntários). Dos 11 estudantes 9 pertenciam a uma mesma turma de $3^{3}$ série, a qual mais da metade se autodeclarava lgbt, um de uma turma de $2^{\mathrm{a}}$ série e outra de outra turma de $3^{\mathrm{a}}$ série do ensino médio integrado. Embora a questão sobre a orientação sexual ter sido a mais central, dada a identidade e reivindicação dos próprios estudantes, desde o início a identidade de gênero e a orientação sexual não foram critérios para pertencimento e adesão ao projeto.

O projeto foi realizado durante os meses de março a dezembro de 2019 e o desenho e execução das atividades práticas junto aos estudantes foram desenvolvidos em duas iniciativas, que se complementaram. Ao longo dos meses, foram realizados encontros formativos e atividades abertas ao nosso público-alvo, outros jovens estudantes do ensino médio integrado da unidade Maracanã do CEFETRJ.

Os encontros formativos foram realizados para o exercício da interface entre a teoria e a vivência de cada estudante em torno dos temas abordados, assim como para levantamento de suas demandas. Esses encontros eram semanais - à exceção das semanas de provas quando não ocorriam - e consistiam em reuniões de formação e planejamento internos, com a presença dos estudantes e das coordenadoras. Os temas abordados foram selecionados a partir de demandas elencadas pelos estudantes durante esses encontros. Diante das propostas, eram feitas discussões teórico-práticas sobre o assunto e planejamento de ações para as atividades abertas, que constituíram em espaços de debates e de intervenções junto a outros estudantes do ensino médio integrado. 


\section{RESULTADOS E DISCUSSÕES}

Um dos resultados dessa experiência foi a confecção do Dicionário de Sexualidade e Juventude com verbetes que compõem o universo da sexualidade que também coincidem com os conceitos estruturadores do próprio projeto: verbetes relacionados à identidade de gênero, orientação e afetividade sexual e movimentos sociais relacionados à sexualidade.

O objetivo do Dicionário foi o de contribuir com o desenvolvimento de uma produção científica adaptada a uma linguagem clara e direta sobre conceitos que compõem o universo da sexualidade: confeccionado pelos próprios estudantes e endereçado a outros jovens. Todo o processo de elaboração foi realizado ou teve participação dos estudantes integrantes do projeto, desde a escolha dos verbetes, a pesquisa e análise bibliográfica, até a escrita e revisão, além da seleção de imagens que ilustram 0 verbete. A confecção de cada verbete foi realizada de forma colaborativa e integrada, de modo a incentivar o trabalho cooperativo (AUTOR, 2019a).

A $1^{\text {a }}$ edição do Dicionário de Sexualidade e Juventude envolveu todos os estudantes/autores integrantes e foi lançada na Semana de Ensino Pesquisa e Extensão do CEFET/RJ (SEPEX 2019). Composto por 34 verbetes, o Dicionário foi registrado (VALENÇA; CARVALHO, 2019b) e atualmente está disponível na plataforma de publicação ISSUU Composto por 34 verbetes, atualmente o Dicionário está disponível na plataforma de publicação ISSUU, onde pode ser acessado de forma gratuita ${ }^{1}$.

Figura 1: Capa (à esquerda) e páginas do "Dicionário de Juventude e Sexualidade" $1^{\underline{a}}$ edição
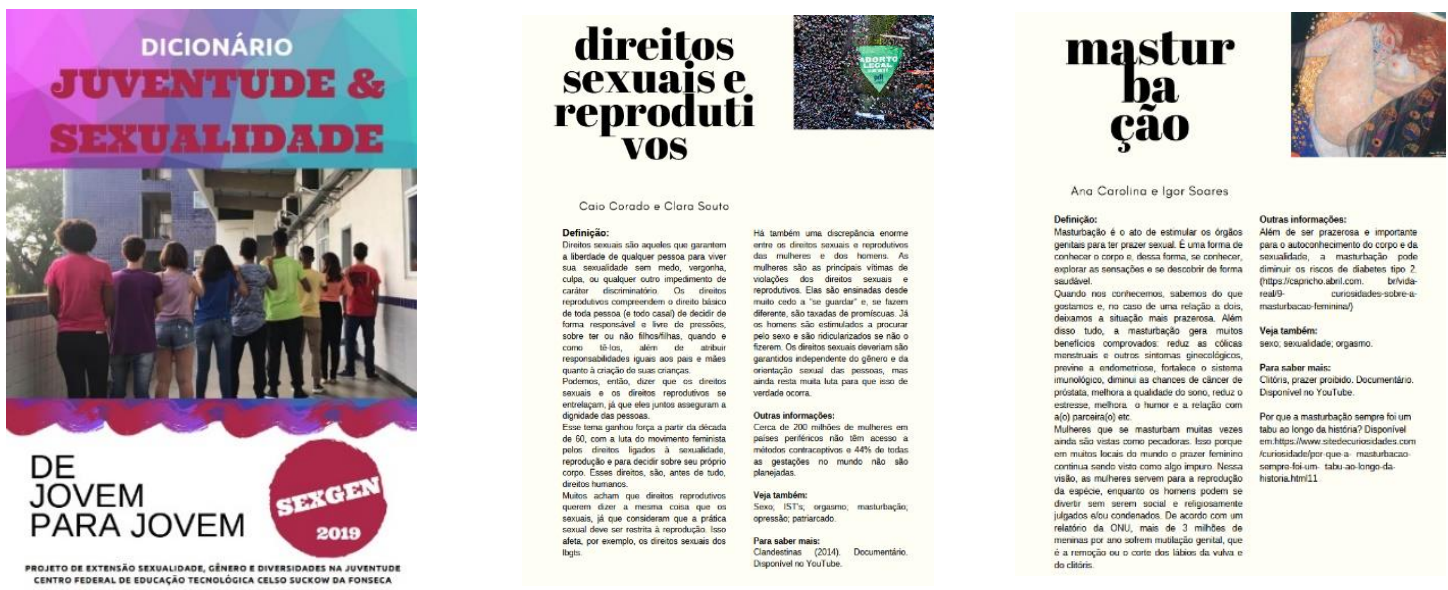

Fonte: "Dicionário de Juventude e Sexualidade"

\footnotetext{
${ }^{1}$ Dadas as potencialidades frente às demandas dos estudantes envolvidos diretamente na confecção do Dicionário bem como os demais jovens estudantes, nosso público-alvo, atualmente estamos dando seguimento aos processos de pesquisa e estudos que envolvem a inserção de novos verbetes e a atualização dos verbetes existentes, além da necessidade de expansão dos mecanismos de divulgação ampla da obra e de criação de ambientes virtuais colaborativos de interação dos usuários do Dicionário.
} 
Desde que foi lançado, em outubro de 2019, há uma reivindicação latente para utilização do dicionário por professores em escolas, dentro e fora do CEFET-RJ. Esse fator pode estar relacionado à carência de materiais acessíveis e sistematizados sobre a temática.

Também em sintonia com o referencial teórico-metodológico eleito, as ações a seguir foram realizadas junto a outros estudantes do ensino médio integrado. A mesa redonda "Sexualidade em tempos de conservadorismo: uma conversa entre jovens" foi baseada no formato de uma conversa entre jovens e teve como objetivo abordar assuntos que envolvem a vida sexual, como gravidez na adolescência, as infecções sexualmente transmissíveis - as IST's - educação sexual, identidade, orientação e diversidade sexual e questões de gênero.

Cientes da importância de buscar a compreensão, os significados e dúvidas dos próprios jovens, a abordagem utilizada para tratar sobre a temática da sexualidade foi pautada em metodologia que facilitou a aproximação e o diálogo com o adolescente, visto que é uma conversa de jovem para jovem. Também foram realizadas as mesas "Feminismos, Política e Sexualidade" ${ }^{2}$, com o enfoque sobre as formas de violência contra as mulheres e as formas de resistência; "Juventude e Sexualidade: entre o acolhimento e a rejeição", acerca do direito de vivenciar as diferentes manifestações de sua sexualidade; o cinedebate "Você é o melhor pra mim", sobre a realidade periférica da questão racial e LGBT.

Figura 2: "Sexualidade em tempos de conservadorismo: uma conversa entre jovens". Em 22 de outubro de 2019

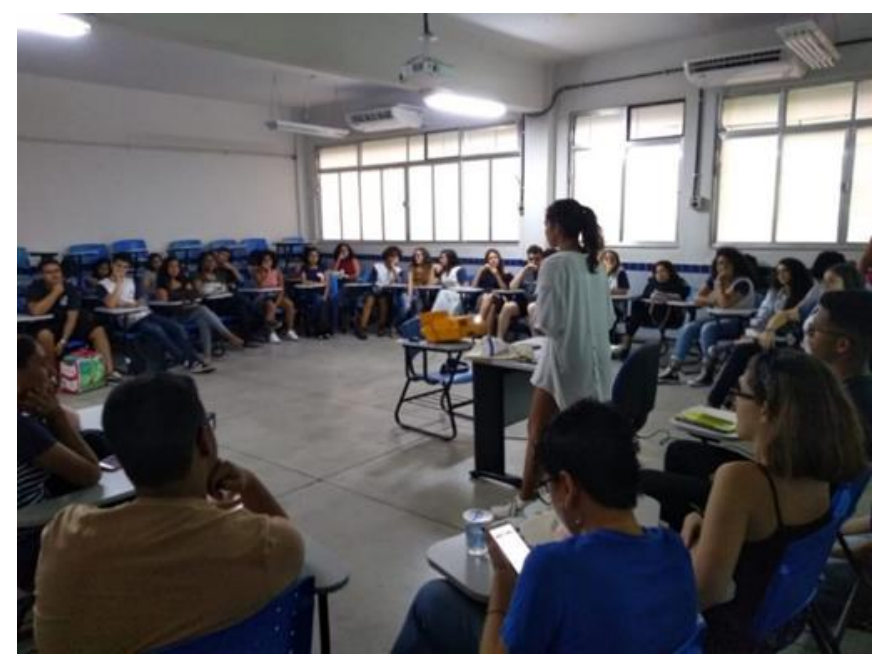

Fonte: Dados da pesquisa.

A exposição "IST's - de jovem para jovem: diálogos e educação a partir da sensibilização artística e da produção de material" foi realizada durante SEPEX 2019 e teve como objetivo aproximar essas informações ao público jovem que, muitas vezes, inicia sua vida sexual sem muito conhecimento tanto sobre seu próprio corpo quanto sobre os novos riscos a que está suscetível. Por meio de uma linguagem mais direta e do uso de modelos e materiais mais interativos e dinâmicos, foram abordadas

\footnotetext{
${ }^{2}$ Debate realizado em parceria com as coordenações de Biologia e de Sociologia da unidade Maracanã do CEFET-RJ.
} 
a questão ao autoconhecimento sobre o corpo, as formas de prevenção e contágio das IST's e métodos anticonceptivos.

A atividade buscou dar enfoque à abordagem não heteronormativa, que é usual em grande parte das atividades que envolvem a educação sexual. O objetivo foi possibilitar outras percepções e sensibilizar os jovens para métodos contraceptivos muitos dos quais desconhecidos pela maioria dos jovens, como a camisinha feminina e prevenção de IST's envolvendo sexo oral.

Os estudantes produziram um panfleto para o público jovem sobre as IST's, um jogo sobre formas de contágio e prevenção, além de materiais didáticos lúdicos para a abordagem da educação sexual, como forma de contrastar com os tradicionais modelos biológicos. Além disso durante os dias de exposição na SEPEX o stand do projeto se apresentou como um espaço plural e de acolhimento das diversidades: a partir das exposições e da estética do espaço outro objetivo foi o de gerar conscientização do público e reflexões sobre autoaceitação e respeito às diferentes manifestações afetivas e de identidade de gênero e orientação sexual.

Figura 3: Exposição "IST's - de jovem para jovem: diálogos e educação a partir da sensibilização artística e da produção de material". Em 23 a 25 de outubro de 2019.

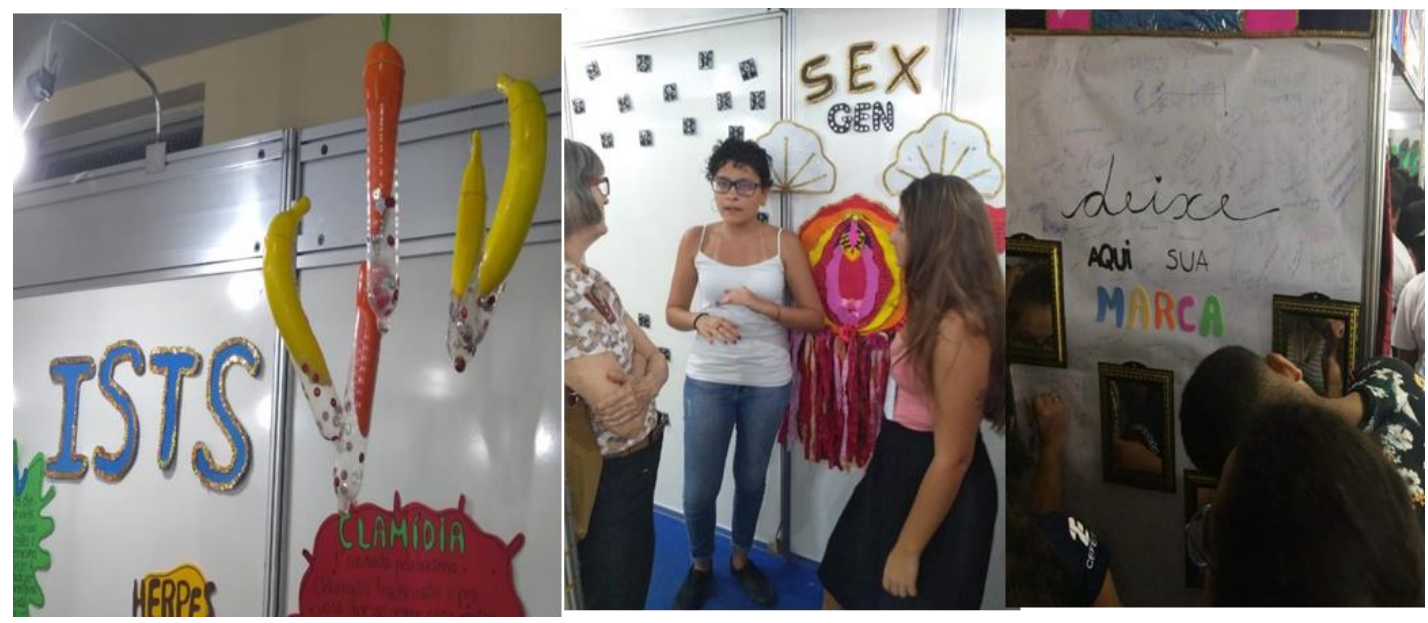

Fonte: Dados da pesquisa.

Como resultado as atividades desenvolvidas pelo projeto ao longo do ano observamos que um avanço na criação de espaços de discussão e reflexão sobre a temática da sexualidade no interior do CEFET-RJ.

O projeto teve como eixo o protagonismo estudantil através da intermediação realizada pelos estudantes integrantes do projeto junto aos outros estudantes que, sob supervisão das coordenadoras, melhor possibilitou o estabelecimento de relações de confiança entre os jovens. Por terem a mesma faixa etária e partilharem diversas experiências comuns, as relações estabelecidas tenderam a ser mais simétricas, o que constituiu em maiores chances de sucesso das ações desenvolvidas e de impacto positivo sobre os estudantes.

A maioria dos estudantes que integrou o projeto destacou seu engajamento a partir de justificativas que extrapolaram motivações puramente individuais, apresentando, em falas durante conversas informais, momentos de avaliação coletiva 
e atividades abertas a outros estudantes, a urgência de abordar a educação sexual, a sexualidade e as questões de gênero no contexto escolar em que se inseriam. Além disso, percebemos que a existência de vínculos de amizade construídos anteriormente ao projeto também foi importante para o engajamento e a adesão por parte desses estudantes.

Ademais, concluímos que o projeto não é algo pronto e fechado. Embora tenha um eixo estruturante, suas estratégias e direcionamentos estão suscetíveis a seguir caminhos orientados pelas demandas dos estudantes integrantes do projeto e do público participante, de acordo com suas características, expectativas e experiências pessoais e coletivas. Deste modo, se em determinada configuração, os integrantes são em sua maioria lgbt's, os interesses estão muito mais em problematizar a questão da aceitação social e familiar, por exemplo.

No fim do ano de 2019, um grupo de estudantes meninas apresentou interesse em aderir ao projeto no ano de 2020. Suas preocupações iniciais estavam em torno das questões de gênero, do sexismo nas ciências e dos casos de feminicídio que vêm crescendo no Brasil. Compreendeu-se ser este o papel institucional do projeto: dar voz aos interesses que se apresentam buscando incluir todas e todos, caminhando na direção de uma educação mais plural, digna e inclusiva.

\section{CONSIDERAÇÕES FINAIS}

O projeto baseou-se no pressuposto da educação em direitos humanos, no qual se busca a emancipação dos sujeitos e a transformação social, e na educação laica, onde os temas de ensino são discutidos com base em literatura científica e não são cerceados por questões religiosas ou de qualquer ordem. Envolveram-se na experiência estudantes, docentes, técnicos-administrativos e terceirizados da instituição, além de convidados externos que, interessados nas temáticas abordadas e cientes da relevância das discussões promovidas, abraçaram o projeto. Não raro, houve depoimentos pessoais positivos sobre as atividades desenvolvidas.

Por fim, entendemos que a formação profissional, de caráter científica, humanista e cultural, não pode estar dissociada do enfrentamento de racismos, machismos, homofobias e outras opressões que se fazem presentes na sociedade e que repercutem no espaço escolar. As ações advindas com o projeto proporcionam produção de conhecimento a partir do vivido, o que nos possibilita ampliar o olhar pedagógico. Com base nisso, mais que um projeto que aborda a ampla temática da sexualidade na juventude, esta iniciativa traz em si possibilidades reais de integração curricular entre as disciplinas de Biologia e Sociologia.

Conforme exposto, a sexualidade é uma dimensão constitutiva fundamental da vida de mulheres e homens e envolve práticas e afetividades que estão relacionadas ao exercício da liberdade e à saúde. Deste modo, para além da presença das temáticas sobre gênero e sexualidade na educação sexual nas escolas, é nosso desafio construir uma educação profissional e tecnológica que inclua as experiências das jovens estudantes mulheres e lgbt's. É nesse sentido que o gênero precisa ser desenvolvido como uma categoria de análise. Sem dúvida, as interseções com as questões étnico-raciais e de classe precisam se aliar às questões de gênero e são cruciais para uma educação na perspectiva dos direitos humanos. Trata-se, portanto, 
de uma concepção sobre a escola e a educação que contribui e incentiva o protagonismo das/dos jovens estudantes como sujeitos históricos.

\section{REFERÊNCIAS}

ANDRADE, M. P. et al. Promoção da saúde sexual e reprodutiva de puérperas adolescentes: abordagem educativa baseada nos círculos de cultura de Paulo Freire. Sanare.; v. 11, n. 1, p. 38- 44, 2012.

BAUMFELD, T. S. et al. Autonomia do Cuidado: Interlocução Afetivo-Sexual com Adolescentes no PET-Saúde. Rev Bras Educ Med.; v. 36, n. 1, p. 71-80, 2012.

BEHRENS, M. A. Projetos de aprendizagem colaborativa num paradigma emergente. In: Novas Tecnologias e Mediação Pedagógica. São Paulo: Papirus, 2002.

BENEVIDES, M. V. Educação em Direitos Humanos: de que se trata? Palestra de abertura do Seminário de Educação em Direitos Humanos, São Paulo, 18/02/2000.

BUTLER, J. Le pouvoir des mots: politique du performatif. Paris: Éditions Amsterdam, 2004.

BRASIL. Ministério da Saúde. Boletim Epidemiológico HIV-AIDS. Bol Epidemiol.; v. 1, n. 1, p. 1-60, dez., 2012.

CANDAU, V. M. Direitos humanos, educação e interculturalidade: as tensões entre igualdade e diferença. Revista Brasileira de Educação. v. 13 n. 37 jan./abr. 2008.

COGHLAN, D.; BRANNICK, T. Doing action research in your own organization. 2nd ed. London: Sage. 2008.

ESTÊVÃO, C. A. V. Justiça complexa e educação: uma reflexão sobre a dialectologia da justiça em educação. Revista Crítica de Ciências Sociais, n. 64, p. 107-134, dez. 2002a.

\section{ESTÊVÃO, C. A. V.. Globalização, metáforas organizacionais e mudança} educacional. Dilemas e desafios. Porto: Edições ASA, 2002b.

FOUCAULT, M. História da Sexualidade I: A Vontade de Saber. Trad.: Maria Thereza da Costa Albuquerque e J. A. Guilhon Albuquerque. 15a edição. Rio de janeiro: Graal, 2003.

HIRATA, H. Tecnologia, formação profissional e relações de gênero no trabalho. Revista Educação e Tecnologia. N.6. Belo Horizonte, 2003.

JUNIOR, D. R.; OSWALD, M. L. M. B.; POCAHY, F. A. Gênero, sexualidade e juventude(s) Problematizações sobre heteronormatividade e cotidiano escolar. Civitas, Porto Alegre, v. 18, n. 1, p. 124-137, 2018.

LOURO, G. Corpo, gênero e sexualidade. Um debate contemporâneo na

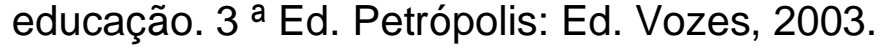

MACEDO, S.R.H.; MIRANDA, F.A.N.; PESSOA JÚNIOR, J.M.; NÓBREGA, V.K.M. Adolescência e sexualidade: scripts sexuais a partir das representações sociais.

Revista Brasileira de Enfermagem. 66(1): 103-109. 2013. 
POCAHY, Fernando. Deuses e Monstros: envelhecimento e (homo)sexualidade nas tramas da abjeção. Bagoas - Estudos Gays: gênero e sexualidades, v. 7, n. 10, p. 133-155, 2013.

SAVIANI, D. Trabalho e educação: fundamentos ontológicos e históricos. Revista Brasileira de Educação. Rio de Janeiro, v. 12, n. 34, p. 152-165, Abr. 2007. Disponível em: $<$ http://www.scielo.br/scielo.php?script=sci_arttext\&pid=S1413$24782007000100012 \&$ Ing=en\&nrm=iso>. Acesso em: 22 abr. 2020.

SCOTT, J. Gênero como categoria útil de análise histórica. Educação e Realidade, v. 20, n. 2, 1995. Disponível em:

https://seer.ufrgs.br/educacaoerealidade/article/view/71721/40667. Acesso em: 25 abr. 2020.

SPOSITO, M.; GALVÃO, I. A experiência e as percepções de jovens na vida escolar na encruzilhada das aprendizagens: o conhecimento, a indisciplina, a violência.

Perspectiva, Florianópolis, v. 22, n. 02, p. 345-380, jul./dez.2004.

VALENÇA, C. R.; CARVALHO, K. L. Sexualidade, Gênero e Diversidades na Juventude: Integrando Biologia e Sociologia. In: II Encontro Intercampi de Educação Profissional do CEFET/RJ, 2019, Rio de Janeiro. Anais do II Encontro Intercampi de Educação Profissional do CEFET/RJ: Educação e Resistência. Rio de Janeiro: CEFET/RJ, 2019a, p. 108-111.

VALENÇA, C. R.; CARVALHO, K. L. (Orgs.). Dicionário Juventude e Sexualidade. 1aㅡ ed. Rio de Janeiro: CEFET/RJ, 2019b. Disponível em: <http://www.cefetrj.br/attachments/article/5257/Dicion\%C3\%A1 rio\%20juventude\%20e\%20sexualidade \%20cefet\%202019.pdf>. Acesso em: 10 mai. 2021.

THIOLLENT, M. Metodologia da Pesquisa-ação. 14ª edição São Paulo: Cortez Editora, 2005. 